\title{
Materials Review
}

The Bilingual Educational Services Catalog is very different by comparison. It is larger, glossier, and specifically geared to the bilingual education of Spanish-speaking students, particularly Chicanos and Puerto Ricans. It represents a single ordering house. Note that many of these bilingual materials can be very useful for teaching Spanish to English speakers on the elementary and secondary levels. The excellent cultural materials are primarily Mexican oriented, with some Puerto Rican background. There is a good game section with actual games illustrated. The CPS Directory tells only where these can be obtaired and, incidentally, does not include this source. The Record section, although limited, is made up of first-class recordings, geographically varied, and includes such contemporaries as Vicki Carr and Joan Baez singing in Spanish. Other listings are: Books, Audiovisuals (by level), Reading Programs (including English as a foreign language), Spanish Programs, Teacher Aids, and a wealth of well indexed materials. The quality of the materials selected from other companies inspires general confidence and many items are clearly illustrated. In short, it is a very valuable catalog for the growing interest in Spanish bilingual education.

\author{
W. J. Cameron \\ Ohio University
}

FOR SALE: Tandberg language laboratory. 25 student booths equipped for audio-active listing plus 10 booths equipped with Tandberg Model 1021 tape recorders. Telex Model 1021 audio-active headsets throughout. 10 magnacord ART tape transports and associated equipment provide master program sources. All equipment purchased new in 1968, has light use and was completely overhauled last year. Technical specifications and photos available on request. Will be sold "where is-as is". Best offer. Contact Mr. Leslie Briggs, Purchasing Agent, The Phillips Exeter Academy, Exeter N:H. 03833. (603) 772-4311 - Ext. 248. 